\title{
A EDUCAÇÃo em SAÚde No AMBIENTE ESCOLAR: UM CONVITE À REFLEXÃO
}

\author{
Health education in school environment: a call for reflection
}

RESUMO O presente artigo apresenta-se como um convite à reflexão acerca da educação em saúde no ambiente escolar, com o objetivo de refletir sobre os principais desafios para sua efetivação. A fim de atender ao que se propõe, realizou-se um estudo de natureza bibliográfica, a partir de trabalhos publicados nas principais bases de dados, entre 2010 e 2015. Com base no levantamento realizado, identificou-se a necessidade em superar o ensino tradicionalista; considerar a realização de ações numa concepção dialógica entre escolas e serviços de saúde; envolver todos os segmentos da sociedade, partindo de uma perspectiva interdisciplinar e contextualizada, além da necessidade em fortalecer as políticas educacionais de formação dos educadores. Assim, de forma crítico-reflexiva, este artigo apresenta discussões importantes para a construção e/ou consolidação da educação em saúde nas escolas, esperando-se que possa contribuir de forma efetiva nas ações desenvolvidas no decorrer do processo ensino-aprendizagem, bem como na continuidade de novas discussões e pesquisas realizadas na área em estudo.

Palavras-chave: EducaçÃo em SAúde. Ambiente Escolar. EnSINO-APRENDIZAGEM.

ABSTRACT This article is presented as an invitation to reflect on the health education in the school environment which aims to think about the main challenges to its effectiveness. In order to get what is proposed there was a bibliographic study from papers published in the major databases between 2010 and 2015. Based on the conducted survey we identified the need to overcome the traditional teaching; consider doing operations in a dialogical conception between schools and health services; involve all segments of society through an interdisciplinary and contextualized perspective as well as the need to strengthen the educational policies of educators training. Therefore, in a critical and reflective way, this paper presents important discussions for the construction and / or health education consolidation in schools and it is expected to be able to contribute effectively to the actions developed during the teaching-learning process as well as to contribute to further discussions and researches conducted on this study area.

KeYWORdS: HeALTH EdUCATION. SCHOOl ENVIRONMENT. TEACHING AND learning.

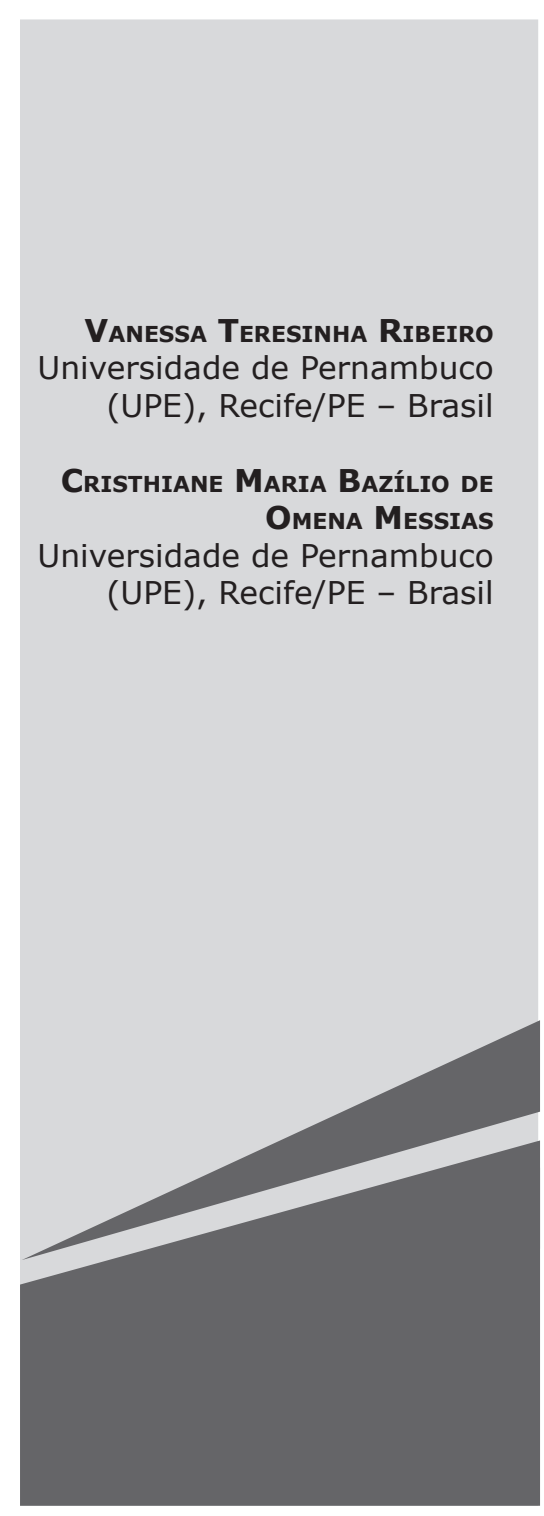




\section{INTRODUÇÃO}

A interação entre educação e saúde representa uma proposta dos temas transversais abordada pelos Parâmetros Curriculares Nacionais (PCN's), assim essa temática deverá permear todas as áreas do conhecimento que integram o currículo escolar, de modo a levar em consideração os vários aspectos do dia a dia da escola para a formação de hábitos e atitudes saudáveis. É importante considerar que não basta apenas transmitir informações, mas também educar para a saúde (BRASIL, 1998).

Torna-se importante compreender que a saúde no ambiente escolar, como objeto de formação, representa uma prerrogativa da cidadania, visto que inclui a qualidade de vida de todos os sujeitos envolvidos. Compreende-se que envolve a conciliação entre um direito público e dever social, assim a educação em saúde é fundamental para a formação de cidadãos conscientes de seu papel social (THOMPSON; BRANDÃO, 2013).

O maior objetivo da educação em saúde no âmbito escolar é fazer com que os alunos sejam capazes de intervir na manutenção e melhoria de suas condições de saúde e da comunidade onde vivem. Para isso, é importante que os educandos construam os conhecimentos necessários para aquisição de tais comportamentos (MOHR, 1995). Assim, reconhece-se o importante papel da escola no sentido de contribuir para uma educação em saúde efetiva, sugerindo-se repensar continuamente as práticas pedagógicas adotadas, de modo a atender cada vez melhor as necessidades dos sujeitos envolvidos.

A escola constitui um espaço privilegiado de interações sociais, apresentando crenças e valores culturais característicos de seu ambiente. O Ministério da Saúde, ao tratar sobre a saúde na escola, afirma que:

Essa dinâmica cultural da escola é extremamente vigorosa, tornando-a um espaço de referências muito importante para crianças e adolescentes, que cada vez mais desenvolvem em seu âmbito ex- periências significativas de socialização e vivência comunitária. A escola é considerada por alguns como o espaço de transição entre o mundo da casa e o mundo mais amplo. Portanto, a cultura escolar configura e é instituinte de práticas socioculturais (inclusive comportamentos) mais amplos que ultrapassam as fronteiras da escola em si mesma [...] (BRASIL, 2009, p.15).

"Uma escola promotora de saúde caracteriza-se como uma escola que busca um estilo de vida, aprendizagem e trabalho que favoreça o desenvolvimento da saúde [...]" (GRACIANO, et al, 2015, p. 37). Isso nos faz refletir sobre a importância da escola incorporar as práticas educativas de saúde em todo o seu ambiente e com todos os sujeitos, estabelecendo uma relação interior e exterior à escola.

Ademais, é importante ressaltar que a concepção de saúde tratada ao longo desse trabalho engloba um entendimento amplo, consistindo não apenas na ausência de doença ou enfermidade, mas, o completo bem-estar físico, mental e social, conforme definição apresentada pela Organização Mundial de Saúde (OMS).

Para tanto, compreendendo que essa discussão é importante no desenvolvimento de práticas educativas efetivas no campo da educação em saúde, essa pesquisa possui como objetivo identificar, a partir de uma reflexão sistematizada, os principais desafios para a estruturação e/ou implantação de práticas de educação em saúde no ambiente escolar.

Partindo desse pressuposto, realizou-se um estudo de natureza bibliográfica, que segundo Marconi e Lakatos (2003, p.183) “[...] propicia o exame de um tema sob novo enfoque ou abordagem, chegando a conclusões inovadoras." Assim, fez-se o mapeamento dos trabalhos produzidos e a sintetização das contribuições destes para a temática em estudo, permitindo, com isso, a cobertura de uma gama de fenômenos (GIL, 2008). 
Utilizou-se como técnica de coleta de dados a consulta de artigos científicos divulgados na base de dados da CAPES (Comissão de Aperfeiçoamento de Pessoal de Nível Superior) e da SciELO (Scientific Electronic Library Online). A escolha das bases de dados ocorreu em razão da amplitude no que tange à abrangência dos periódicos. Foram identificadas 815 (oitocentos e quinze) produções sobre o tema, mediante a pesquisa realizada com os descritores 'Educação em Saúde' e 'Saúde na Escola', no período compreendido entre 2010 e 2015. Após a seleção por título e resumo foram selecionadas 46 (quarenta e seis) produções para a leitura na íntegra.

Realizou-se a leitura e avaliação crítica dos artigos selecionados para verificar se respondiam plenamente ao objetivo da pesquisa. Buscou-se o rigor e as características de cada artigo, sendo constatado que, do universo de 46 (quarenta e seis) produções, apenas 27 (vinte e sete) estudos atendiam aos critérios desejados.

As seleções dos artigos obedeceram aos seguintes critérios de inclusão: artigos publicados em português, com resumos disponíveis nas bases de dados, disponíveis na íntegra online e com abordagem da temática educação em saúde nas escolas. Como critérios de exclusão: artigos publicados nos demais idiomas, sem resumos disponíveis nas bases de dados, não disponíveis na íntegra online e que não respondessem ao objetivo da pesquisa. Com base nos resultados encontrados foi traçada uma discussão a partir de tópicos emergidos desse estudo, conforme apresentados a seguir.

\section{UMA ANÁLISE SOBRE A ESCOLA}

Entende-se a importância do processo educativo como um "[...] instrumento didático e pedagógico de transformação do ser humano, à medida que permite gerar conhecimentos sobre questões bioéticas e humanas de valorização da vida e estímulo à cidadania" (SANTOS F. P. et al, 2011, p. 276). Concomitantemente, "ao compreender o ambiente escolar como um espaço privilegiado de convivência e de interações sociais, e ao relacioná-lo com a promoção da saúde, encontra-se o caminho norteador para a manutenção da saúde" (RAMOS et al, 2013, p.440).

A escola é um espaço de encontro de adolescentes e jovens, onde ocorrem as mais diversas experiências de convivência entre educadores, alunos, pais e funcionários. A comunidade escolar, em seu contexto sociocultural, vivencia o desenvolvimento das práticas pedagógicas operacionalizadas a partir de políticas públicas. Essas políticas têm sido planejadas no sentido de trabalhar os problemas cotidianos com articulação intersetorial. Neste sentido, parcerias entre o Ministério da Saúde e o da Educação são realizadas para efetivar as ações em todas as esferas da gestão pública [...] (GIACOMOZZI, 2012, p.614).

Em uma pesquisa na qual pretendia-se investigar o adolescente, enquanto protagonista em atividades de educação em saúde no espaço escolar, identificou-se que os educandos ainda conviviam numa relação unilateral com os educadores. Levando-se em consideração o número de adolescentes envolvidos na pesquisa, as etapas da ação protagonista (iniciativa, planejamento, execução, avaliação e apropriação dos resultados da ação) e a relação educador-educando, teve-se que, numa escala de $0 \%$ - 100\%, apenas $10,5 \%$ enquadravam-se como educandos autônomos, caracterizando-se como sujeitos ativos no mundo escolar. Os demais se incluíam numa relação de colaboração ou dependência, apontando para a necessidade em inserir os educandos como sujeitos da aprendizagem, tornando-os parte do processo de transformação social, sendo essa não uma solução única, mas parte da solução (SILVA M.; MELLO; CARLOS, 2010). 
É importante que seja proporcionado “[...] um protagonismo juvenil que pode construir novas possibilidades de aprendizagem, promovendo ao mesmo tempo saúde e educação". (SANTOS F.O.; LIMA S., 2015, p.226), tornando os alunos, portanto, construtores e promotores de saúde nas escolas.

Santos F. P. et al (2011) apontam a presença de uma prática pedagógica focada na transmissão do conhecimento, havendo um distanciamento da realidade social e da experiência de vida do aluno, ainda que o discurso atual enfatize uma educação libertadora. A existência de um modelo tradicional proporciona o conhecimento produzido cientificamente, adquirindo-se conteúdos relevantes no processo de ensino e aprendizagem. Por outro lado, o relacionamento entre educador e educando acontece de forma verticalizada, sendo este apenas receptor de informações, sujeito passivo, na qual não se valoriza a importância de seu protagonismo na construção e aplicação de práticas de educação em saúde no seu cotidiano. Mesmo com uma discussão crítica quanto à efetividade dessa prática, pouco se tem feito para a transformação da realidade atual (FIGUEIREDO M.; NETO; LEITE, 2010).

Em contraponto, os mesmos autores apresentam um Modelo Dialógico de educação em saúde, no qual propõe a construção do conhecimento marcado pelo diálogo, em que o educador e educando assumem papel ativo no processo de ensino e aprendizagem, por meio de uma abordagem crítico-reflexiva da realidade (FIGUEIREDO M.; NETO; LEITE, 2010).

Partindo dessa premissa, é fundamental que a escola supere a visão tradicionalista e trabalhe numa perspectiva libertadora, em que se baseia no diálogo, nas trocas e discussões, a partir de uma relação horizontal, de forma a acreditar e potencializar a capacidade de transformação social do educando.

\section{A ESCOLA E OS SERVIÇOS DE SAÚdE}

A escola e os serviços de saúde possuem uma gama de possibilidades para a constru- ção e execução de projetos de educação em saúde, tendo em vista a necessidade local e global, o que poderá envolver desde a mudança de hábitos alimentares para uma vida saudável até os problemas de saúde mais urgentes na sociedade atual, como a AIDS ((Síndrome da Imunodeficiência Adquirida), o consumo de álcool e outras drogas. Mas, é importante considerar o percurso metodológico adotado na execução de tais atividades.

É necessário compreender que as práticas educativas de saúde não se restringem aos profissionais da saúde e aos serviços de saúde, sendo os educadores responsáveis pela construção compartilhada de tais práticas, necessitando, inclusive, da inclusão no Projeto Político Pedagógico da escola (SILVA et al apud FIGUEIREDO T.; MACHADO; ABREU, 2010).

A literatura ainda ressalta que, em se tratando da atenção à saúde na educação básica, a relação saúde e educação nem sempre tem sido harmoniosa, em virtude de ações pontuais e isoladas, focadas no controle e prevenção de doenças, não obtendo os efeitos desejados: a mudança de atitude para uma vida saudável. Para isso, profissionais da saúde necessitam de um olhar crítico da estrutura e funcionamento da escola, considerando a importância do planejar, implementar e avaliar as práticas de educação em saúde nesse ambiente, evitando, assim, ações pontuais (FIGUEIREDO T.; MACHADO; ABREU, 2010). Reforçando esse posicionamento, Souza (2013, p.393) afirma que "as instituições, em geral, ficam reféns de estratégias pontuais, isoladas, de cunho experimental que infelizmente não conseguem se transformar em políticas de Estado."

Corroborando com essa ideia, Dandolini et al (2012) ao relatarem a experiência de desenvolvimento de um instrumento de educação em saúde com alunos do ensino fundamental sobre o uso racional de antibióticos, sugerem a possibilidade de pesquisadores projetarem suas ações a partir de reflexões com os grupos a serem envolvidos, partindo de suas necessidades. Para isso, é imprescin- 
dível a realização das seguintes ações: observação, planejamento, implantação e avaliação de resultados.

Um outro aspecto importante é a valorização da interdisciplinaridade na realização das práticas educativas em saúde, de modo a integrar as diferentes disciplinas e as especificidades de cada área profissional, buscando-se soluções compartilhadas (PEREIRA et al, 2015).

"Os profissionais de saúde, ao se aproximarem do cotidiano das escolas, estarão contribuindo com a intersetorialidade, que deve ocorrer entre os setores saúde e educação, e estarão também delineando estratégias condizentes com a realidade encontrada [...]" (SANTOS F. P. et al, 2011, p. 278).

Cabe aqui citar um projeto realizado por um grupo de enfermeiros numa escola municipal com o objetivo de verificar a acuidade visual dos estudantes e realizar o encaminhamento para exame especializado, diante da necessidade. Detectar a tempo a deficiência visual pode atenuar ou evitar sequelas, justificando, assim, a importância do projeto. Diante da conclusão do mesmo, os enfermeiros reforçaram a necessidade da mobilização entre os docentes e os profissionais da saúde para atuarem em parceria com o governo local. Destacaram a importância dos profissionais (docentes, enfermeiros e médicos) possuírem subsídios para o desenvolvimento de ações na área e apresentaram a necessidade do enfermeiro expandir o seu campo de atuação para as escolas, diante de sua intrínseca capacidade (LAIGNIER; CASTRO; SÁ, 2010).

O projeto de extensão Aprendendo Saúde na Escola, realizado num ambiente escolar de um Centro Municipal de Educação Infantil, na qual pretendia identificar as necessidades e demandas das crianças apresentou resultados positivos na sua execução, obtendo, por exemplo, relatos sobre a diminuição dos episódios de violência doméstica contra a criança. Realizando uma avaliação sobre o projeto, os autores consideraram indispensável a integração dos serviços de saúde com a escola para a solidificação das ações realizadas (MACIEL et al, 2010).
Em pesquisa desenvolvida com o objetivo de realizar o levantamento sobre uso de álcool e outras drogas, bem como as vulnerabilidades relacionadas aos estudantes de escolas públicas participantes do Programa Saúde e Prevenção nas Escolas no município de Florianópolis, foi apresentada uma consideração importante, a saber:

Fica claro, portanto, que a escola não conseguirá sozinha trabalhar com os aspectos de promoção de saúde e prevenção, pois estes aspectos estão intrinsecamente ligados à família do adolescente. Por isso se faz importante articular este trabalho junto a Estratégia de Saúde da Família, para que se possa envolver toda a comunidade nessa reflexão em busca de uma melhoria da qualidade de vida dos estudantes (GIACOMOZZI, 2012, p. 621).

É importante, também, compreender que as instituições de ensino formadoras de profissionais da saúde, ao desenvolverem ações conjuntas nas escolas, possibilitam ao futuro profissional uma experiência fundamental para sua formação. Como exemplo, tem-se uma pesquisa-ação realizada concomitantemente com estudantes de medicina e uma escola municipal, afim de tratar sobre a Autonomia do Cuidado: Interlocução Afetivo-Sexual com Adolescentes no Programa de Educação pelo Trabalho para a Saúde (PET-Saúde), na qual constatou-se que o desenvolvimento do projeto contribuiu para o aprimoramento na formação dos futuros profissionais da saúde (BAUMFELD et al, 2012).

Essa prática nos faz refletir sobre a importância de uma política educacional com a valorização da educação em saúde na formação dos futuros profissionais, de modo a capacitá-los para o exercício pleno da profissão e, portanto, contribuir eficazmente nas ações desenvolvidas pelos serviços de saúde. “Está posto que formar profissionais de saúde com perfil adequado às necessidades sociais é um 
dos maiores desafios do Ensino Superior que ganha dimensão particular e significativa pela natureza do trabalho nesse âmbito" (PEREIRA et al, 2015, p.870).

Assim, diante da responsabilidade que a educação e a saúde encontram-se para a execução de práticas efetivas, compreende-se que tem se tornado imprescindível a realização de uma parceria entre a escola e os serviços de saúde, de modo a realizarem ações conjuntas e contínuas. "Educação e saúde são, portanto, duas faces do mesmo processo, interdependentes e co-construtivas" (FEIO; OLIVEIRA, 2015, p.712).

\section{OS DIVERSOS SEGMENTOS DA SOCIEDADE}

A escola, enquanto promotora de saúde, representa um importante instrumento para uma cidade saudável, a partir da inclusão e participação de todos os sujeitos (SILVA et al apud FIGUEIREDO T.; MACHADO; ABREU, 2010). "Desse modo, faz-se necessário uma interação mais profunda entre escola, família e comunidade [...]" (LIMA; MALACARTE; STRIEDER, 2012, p.173).

Verificou-se na literatura que um grupo de residentes composto por profissionais de áreas distintas (Enfermagem, Farmácia, Fisioterapia, Nutrição, Odontologia, Psicologia e Serviço Social), desenvolveram um projeto de promoção da saúde em escolas da educação infantil e obtiveram bons resultados, na medida em que participaram todos os profissionais citados, crianças, educadores e pais. A construção do projeto ocorreu de forma compartilhada, desenvolvendo diferentes formas de promover a saúde, a partir de atividades intersetoriais e interdisciplinares (RAMOS et al, 2013). Esse exemplo é enfatizado pela literatura, quando afirma que:

As ações voltadas para a implantação da escola como promotora de saúde devem garantir a participação da comunidade escolar como um todo, para estabelecer ambientes favoráveis à saúde, desde o le- vantamento das principais necessidades, identificação das prioridades e elaboração de estratégias para desenvolver uma ação local participativa na comunidade escolar (SILVA R. et al, 2011, p.67).

Corroborando com essa ideia, após uma pesquisa em que se analisa o processo de cooperação entre os agentes de endemia e a escola em áreas favoráveis à reprodução do vetor da dengue em domicílios, os autores da referida pesquisa apresentam uma reflexão importante, a saber:

Investimentos em práticas de educação em saúde são necessários, mas requerem processos contínuos. A ação aqui desenvolvida foi pontual e mobilizou parte dos alunos, o que aponta seu potencial. No entanto, indica também que precisa ser mediada e reforçada por outras ações intersetoriais. O controle do vetor e o levantamento de propostas de intervenção devem envolver todos os segmentos relacionados ao problema: comunidade, trabaIhadores, profissionais da saúde e educação da localidade, bem como representantes políticos. A participação de todos deve ser incentivada, fomentando e mobilizando os diferentes atores na prevenção e no controle da dengue (SILVA P.; MARTINS A.; SCHALL, 2013, p.408).

Em estudo realizado com adolescentes numa escola estadual, na qual executou-se ações de educação em saúde visando a reflexão crítica dos adolescentes sobre as questões relacionadas com o uso abusivo de drogas e comportamentos violentos, os autores, também, destacam a importância das ações integradas no desenvolvimento de programas educativos em saúde, sugerindo o envolvimento individual, familiar, comunitário e social (SILVA K., et al, 2010). 
Dessa forma, "é essencial um processo educativo consistente, que envolva vários, senão todos, os setores da sociedade, trabalhando num mesmo sentido, para que a cidadania seja consolidada e melhor qualidade de vida e saúde seja atingida" (SILVA R. et al, 2011, p.69). "Sublinhamos a ideia central de que a educação não deve ser obrigação estanque à escola e sim, se constituir de compromissos de todos os atores do processo [...]" (LIMA F.; MALACARTE; STRIEDER, 2012, p. 203).

\section{INTERDISCIPLINARIDADE E CONTEXTUALI- ZAÇÃO}

O envolvimento de todas as áreas do conhecimento possibilita ao educando uma visão ampla do que é saúde e de como o indivíduo pode atingir esse melhor estado de saúde. "Não se pode negar a importância da ação interdisciplinar e multidisciplinar da escola e o seu potencial em obter uma condição privilegiada para lidar com a formação em saúde das novas gerações [...]" (LIMA F.; MALACARTE; STRIEDER, 2012, p. 202).

Com isso, as propostas de trabalhos interdisciplinares vêm cada vez mais ganhando destaque, justamente, por compreender que os problemas existentes demandam uma gama de conhecimentos, a partir de diferentes perspectivas. Porém, é importante considerar que muitos destes trabalhos têm seguido por um caminho equivocado, não desenvolvendo, de fato, um trabalho interdisciplinar (PINHÃO; MARTINS I., 2012).

Fourez (Apud PINHÃO; MARTINS I., 2012, p. 824) afirma que:

Existem duas maneiras distintas de se trabalhar. A primeira surge a partir da crença na possibilidade de se elaborar uma superciência que dê conta de abranger todos os aspectos envolvidos em um determinado problema. Uma união deste tipo, muitas vezes, resulta na criação de uma nova disciplina, a qual passa a tratar as questões do cotidiano seguindo seus próprios paradigmas e, invariavelmente, não atinge a complexidade dos problemas cotidianos. Já a segunda não se compromete com a tarefa de elaborar um conhecimento para além das disciplinas particulares, mas busca respostas a partir das especificidades de diferentes disciplinas. Dessa forma, a interdisciplinaridade é concebida como prática, e não como a possibilidade de elaboração de uma superciência. Logo, "o objetivo não será criar uma disciplina científica, nem um discurso universal, mas resolver um problema concreto"

Desse modo, entende-se que a proposta não é a realização de ações pontuais, fragmentadas, que ocorrem isoladamente no ambiente escolar ou mesmo a criação de uma nova disciplina, mas a realização de uma prática dialógica, envolvendo todas as áreas do conhecimento.

Ainda de acordo com Fourez (Apud PINHÃO; MARTINS I., 2012, p. 824), "não podemos atribuir o fracasso da interdisciplinaridade à existência de um currículo disciplinar, mas à inexistência de relação entre as disciplinas escolares [...]." Pensamos que seja necessário rever as práticas pedagógicas adotadas nas escolas, estas necessitam superar o engessamento praticado ao longo dos anos, é preciso um novo direcionamento, uma perspectiva dialógica entre as diferentes áreas do conhecimento.

A escola é um local de troca mútua, em que professores e alunos se integram, a fim de construírem o conhecimento. A educação escolar está relacionada ao trabalho dos professores e dos alunos, tendo como finalidade o caráter coletivo e interdisciplinar para alcançar o saber. É possível oferecer aos adolescentes o pensamento crítico de sua 
condição de vida e de seu processo de adolescer por meio do diálogo (BESERRA et al, 2011, p.1565).

Em se tratando da importância da interdisciplinaridade dentro desse contexto, a literatura ainda reforça essa ideia, afirmando que:

Para promover o desenvolvimento em questões que circundam o tema da saúde é importante que sejam abordadas várias áreas em rede, inclusive com a integração da escola, por meio de suas disciplinas, na promoção de conteúdos adequados, metodologias e abordagem integrada e instrumentos operacionais multidisciplinares validados em sua eficácia para serem desenvolvidos com os estudantes, professores, pais e demais membros da comunidade escolar (LIMA F.; MALACARTE; STRIEDER, 2012, p. 198).

Ademais, Santos M. (2011) retrata a importância dos diversos contextos existentes, sendo estes fundamentais na condução de práticas adequadas de promoção e educação em saúde. Assim, o processo de ensino e aprendizagem torna-se flexível, sendo as práticas repensadas conforme a realidade de vida dos sujeitos envolvidos.

[...] mencionamos como de grande importância a inclusão ou a valorização, enquanto um dos objetivos da escola, a integração ao cotidiano da saúde no contexto no qual se insere, participando dele sob a forma de programas de intervenção desenvolvidos a partir de ações concentradas de modo específico à realidade local, não apenas sobre os problemas vivenciados, mas interferindo na cultura local motivando para a incorporação de elementos que levem a posturas saudáveis, considerando as singularidades e complexidades das pessoas, sua identidade diferenciada, suas aspirações, capacidades e deficiências. $O$ incentivo às atitudes saudáveis não busca a homogeneidade nas posturas, mas a sua incorporação às culturas já existentes (LIMA F.; MALACARTE; STRIEDER, 2012, p. 199).

$\mathrm{Na}$ pesquisa intitulada "Programa de educação nutricional em escola de ensino fundamental de zona rural", na qual possuía como objetivo apresentar métodos e tecnologias de intervenção em educação alimentar e nutricional, os resultados demonstraram que é possível realizar um programa de incentivo ao consumo de alimentos produzidos na região em que a escola se encontra inserida. Além disso, essa prática despertou um grande interesse por parte dos alunos, conforme apresentado na conclusão do trabalho (BOOG, 2010):

[...] Houve grande interesse dos alunos pelas atividades realizadas porque elas refletiam o seu próprio cotidiano e valorizavam o trabalho, a história, a identidade cultural e a autoestima das famílias de fruticultores. A fruta foi ressignificada enquanto direito do próprio agricultor que a produz (BOOG, 2010, p.1016).

Além disso, GREGO et al (2011, p. 499) tratam sobre a utilização da técnica do autoexame como instrumento pedagógico de autoconhecimento de forma a promover

[...] uma via de subjetivação entre a ação de construção de conceito de si e a promoção de autocuidado em seu cotidiano, contextualizando a informação em relação ao câncer de mama e, consequentemente, compreender os benefícios de desenvolver, incorporar hábitos saudáveis para melhoria da qualidade de vida adulta. 
É justamente a compreensão do meio em que os sujeitos estão inseridos que possibilita o desenvolvimento de atividades adequadas para a promoção da educação em saúde (SANTOS M. et al, 2011). A educação em saúde deve extrapolar o seu espaço convencional, visto que não pode ser entendida como "[...] um processo que se confina às paredes de uma escola, de um hospital ou de um centro de saúde, numa visão exclusivamente formal de educação" (FEIO; OLIVEIRA, 2015, p.712).

$O$ ensino contextualizado é fundamental para que se desenvolva no educando a preocupação com o outro, de modo a obter um compromisso não só individual, mas também coletivo. "Nesse sentido, ao criar condições para que os outros se realizem, cada indivíduo contribui para a sua própria realização" (FEIO; OLIVEIRA, 2015, pp. 706-707).

Pensando na necessidade da interdisciplinaridade para a construção de uma formação efetiva e na preocupação com o local, entende-se que deve ser estabelecido, também, uma relação com o todo, permitindo ao aluno uma análise complexa da realidade. Assim, a educação em saúde deve ser entendida como um projeto de toda a escola, constituindo-se como um processo articulado entre as diferentes áreas do conhecimento, estabelecendo uma relação contínua com as vivências dos educandos e, consequentemente, com o meio em que a escola se encontra inserida, sem esquecer de conceder uma relação com o global.

\section{O EDUCADOR NO PROCESSO DE FORMAÇÃO}

"A figura do professor representa um modelo e um exemplo de hábitos e condutas, daí a importância do papel que desempenha em valorizar e estimular as práticas de higiene e saúde" (SILVA R. et al, 2011, p.65). É necessário que o educador reconheça o seu valioso papel dentro e fora da escola, tanto para a promoção da saúde dos educandos como da comunidade em volta.

No entanto, é pertinente considerar as dificuldades enfrentadas pelo educador nesse processo de ensino e aprendizagem. Silva C. et al (2010), ao realizarem uma análise sobre a trajetória da educação em saúde no Brasil, afirmam que a educação em saúde não vem ocorrendo na prática dos serviços e apontam como um dos grandes desafios a formação humana orientada para a educação popular e o respeito aos saberes da comunidade, possibilitando a busca para o que eles chamam de cidadania compartilhada. Assim, reforçam a necessidade da formação de indivíduos, de forma a capacitá-los para a efetivação das práticas de educação em saúde. Souza (2013, p. 393) também apresenta uma preocupação quanto "[...] à habilidade dos educadores para desenvolver estratégias de promoção da saúde e nortear os pré-escolares com medidas de autocuidado".

Ainda de acordo com a literatura, os professores não recebem em sua formação inicial um preparo para trabalhar essa temática em sala de aula, tornando-os inseguros no exercício de suas práticas, o que leva, principalmente, ao surgimento de um trabalho fragmentado, focado na transmissão do conhecimento, além da atribuição da reponsabilidade dessa temática ao professor de ciências (PINHÃO; MARTINS I., 2012).

Em pesquisa na qual possuía como objetivo investigar as opiniões e o conhecimento dos concluintes de um curso de Pedagogia sobre a educação em saúde bucal, os autores concluem que os recém-formados reconhecem a importância dessa temática, porém o conhecimento dos mesmos sobre o assunto é insatisfatório e abordam a importância de se integrar a temática de saúde bucal nos currículos das instituições formadoras de professores (GARBIN, 2012). Esse posicionamento nos remete a uma reflexão mais ampla, envolvendo os diversos temas que englobam a educação em saúde, bem como todos os cursos de formação docente, na medida em que se reconhece a importância de uma formação capaz de atender as necessidades da sociedade atual. Em consonância com essa discussão, a literatura ainda afirma que: 
O desconhecimento dos professores em geral, sobre as questões mais básicas se enraíza no processo de formação inicial e se alonga na formação continuada. No interior da escola, a ausência de projetos amplos direcionados pelos professores, cuja formação é insuficiente para desenvolver o tema, a educação em saúde é por vezes amenizada por visitas técnicas de profissionais de saúde que tentam preparar tais professores de forma pontual para atuar, por exemplo, no incentivo aos alunos para "escovação correta dos dentes", "verificação oftalmológica", "oficinas de sexualidade", "combate às drogas", entre outros. Na perspectiva desenvolvida no presente texto, tais momentos de formação geram ações ineficientes, momentâneas e localizadas, cujos resultados são ínfimos em relação às necessidades da sociedade para uma educação voltada à saúde, na perspectiva do bem-estar físico, mental e social (LIMA F.; MALACARTE; STRIEDER, 2012, p. 201).

"Os professores devem ser preparados para discutir questões de saúde, higiene e alimentação, de maneira crítica e contextualizada, vinculando saúde às condições de vida e direitos do cidadão" (SILVA R. et al, 2011, p.67). É importante considerar a "[...] potencialização da ação do educador em sala de aula - o que se dá através da oferta de cursos de formação continuada ou atualização voltada para os mesmos" (FIGUEIREDO T.; MACHADO; ABREU, 2010, p.401). Ainda sobre a formação docente, Silveira et al (2012) sugerem a realização de projetos de extensão na área da educação em saúde, representando-se, também, como uma forma de contribuição social da universidade, "[...] possibilitando, a universitários e professores, a saída dos muros acadêmicos para a aprendizagem e ensino no real e complexo trabalho interdisciplinar em saúde" (PEREIRA et al, 2015, p.876).

Diante do exposto, é possível verificar que há uma indicação para a difusão da educação em saúde tanto na formação inicial quanto na continuada dos educadores. É sugestivo que os mesmos "[...] além de preparados, eles estejam capacitados para atuarem também como agentes promotores de saúde nas escolas" (GARBIN, 2012, p.460).

Aqui reforçamos o importante papel que o educador pode desenvolver, mas, principalmente, que se tenha um trabalho com a mais estreita cooperação de todos. Assim, é fundamental uma relação de parceria entre os serviços de saúde, família, comunidade e escola.

Um outro aspecto a ser considerado é a efetiva participação e parceria dos profissionais da saúde na realização de projetos educativos em saúde, de modo a alcançar, juntos, os objetivos desejados. Em uma pesquisa que trata sobre a abordagem do álcool no contexto do ensino fundamental, os autores reforçam esse posicionamento apresentando a seguinte afirmação: "Sugere-se, portanto, a participação do enfermeiro como educador de saúde nesse processo de transformação da escola, com aparato técnico-científico e legal [...]" (FELIPE; GOMES, 2010, p.7).

Além disso, acreditamos que é indispensável o envolvimento dos professores de Educação Física, instigando e difundindo projetos de educação em saúde na escola, no sentido de apresentarem uma maior sustentação na criação, execução e avaliação, tendo em vista a sua intrínseca formação profissional.

\section{CONSIDERAÇÕES FINAIS}

Diante da pesquisa realizada, constatou-se que tem se tornado necessária a superação da visão tradicionalista que ainda impera no processo de formação dos indivíduos e se configura de forma marcante no processo de ensino e aprendizagem, bem como a necessidade em se realizar a construção compartilhada do conhecimento, de forma a envolver a escola e os serviços de saúde. 
Identificamos a necessidade da participação de todos os segmentos da sociedade (escola, família, serviços de saúde e comunidade), bem como o estabelecimento de uma atitude interdisciplinar e contextualizada, levando-se em consideração, portanto, as diferentes áreas do conhecimento e a realidade em que os sujeitos encontram-se inseridos.

Partindo do reconhecimento dos educadores enquanto agentes multiplicadores inseridos no processo de ensino e aprendizagem, consideramos importante uma política educacional vigorosa e comprometida com a formação inicial e continuada dos mesmos. Reforçamos a necessidade da efetiva participação dos professores de Educação Física e dos profissionais da saúde no desenvolvimento de projetos educativos em saúde.
Portanto, as escolas possuem o desafio de trabalhar a educação em saúde por meio de uma proposta libertadora, comprometida com a formação efetiva do aluno, de forma a orientar-se para ações cuja essência esteja na melhoria da qualidade de vida dos sujeitos e da sociedade atual.

Finalmente, é importante esclarecer que não houve aqui uma preocupação em exaurir o tema, sendo inviável devido os limites deste trabalho. No entanto, o que nos interessou foi realizar uma discussão em torno dos principais desafios apresentados para a estruturação e/ ou implantação de uma educação em saúde efetiva nas escolas. O debate sobre essa temática tem avançado nos últimos anos, assim, espera-se que este trabalho possa contribuir para novas discussões e pesquisas futuras.

\section{REFERÊNCIAS}

BAUMFELD, Tiago Soares et al. Autonomia do cuidado: interlocução afetivo-sexual com adolescentes no PET-Saúde. Revista Brasileira de Educação Médica, Rio de Janeiro, v.36, n.1, p. 71-80. 2012. Disponível em: <http://dx.doi.org/10.1590/S0100-55022012000200010>. Acesso em: 20 out. 2015.

BESERRA, Eveline Pinheiro et al. Pedagogia freireana como método de prevenção de doenças. Ciência \& Saúde Coletiva, Rio de Janeiro, v.16, n.1, p. 1563-1570. 2011. Disponível em: <http:// www.scielo.br/scielo.php?script=sci_arttext\&pid=S1413-81232011000700092>. Acesso em: 20 out. 2015.

BOOG, Maria Cristina Faber. Programa de educação nutricional em escola de ensino fundamental de zona rural. Revista de Nutrição. Campinas, v. 23, n. 6, p. 1005-1017, nov./dez. 2010. Disponível em: <http://dx.doi.org/10.1590/S1415-52732010000600007>. Acesso em: 20 out. 2015.

BRASIL. Ministério da Educação. Secretaria de Educação Fundamental. Parâmetros Curriculares Nacionais: Temas Transversal Saúde. Brasília, 1998. 42 p.

BRASIL. Ministério da Saúde. Secretaria de Atenção à Saúde. Departamento de Atenção Básica. Cadernos de Atenção Básica Saúde na Escola n. 24. Brasília, 2009. 96 p.

DANDOLINI, Bruna Werner et al. Uso racional de antibióticos: uma experiência para educação em saúde com escolares. Ciência \& Saúde Coletiva, Rio de Janeiro, v.17, n.5, p. 1323-1331. 2012. Disponível em: <http://dx.doi.org/10.1590/S1413-81232012000500026>. Acesso em: 20 out. 2015.

FEIO, Ana; OLIVEIRA, Clara Costa. Confluências e divergências conceituais em educação em saúde. Saude e Sociedade, São Paulo, v.24, n.2, p. 703-715. 2015. Disponível em: <http://dx.doi. org/10.1590/S0104-12902015000200024>. Acesso em: 21 dez. 2015.

FELIPE, Ingryd Cunha Ventura Felipe; GOMES, Antonio Marcos Tosoli Gomes. A abordagem do álcool no contexto do ensino fundamental: a reconstrução socioimaginária dos docentes. Re- 
vista Latino-Americana de Enfermagem, Ribeirão Preto, v.18, n.5, p. 1-8, set./out. 2010. Disponível em: <http://www.revistas.usp.br/rlae/article/view/4241>. Acesso em: 06 nov. 2015.

FIGUEIREDO, Maria Fernanda Santos; NETO, João Felício Rodrigues; LEITE, Maísa Tavares Souza. Modelos aplicados às atividades de educação em saúde. Revista Brasileira de Enfermagem, Brasília, v. 63, n. 1, pp. 117-121, jan./fev. 2010. Disponível em: <http://webcache.googleusercontent.com/search?q=cache:4V5JxmCPn8sJ:www.scielo.br/pdf/reben/v63n1/v63n1a19. $p d f+\& c d=1 \& h l=p t-B R \& c t=c l n k \& g l=b r>$. Acesso em: 05 nov. 2015.

FIGUEIREDO, Túlio Alberto Martins de; MACHADO, Vera Lúcia Taqueti; ABREU, Margaret Mirian Scherrer de. A saúde na escola: um breve resgate histórico. Ciência \& Saúde Coletiva, Rio de Janeiro, v.15, n.2, p. 397-402. 2010. Disponível em: <http://dx.doi.org/10.1590/S141381232010000200015>. Acesso em: 05 nov. 2015.

GARBIN, Cléa Adas Saliba et al. Conhecimento sobre saúde bucal por concluintes de pedagogia. Trabalho, educação e saúde, Rio de Janeiro, v.10, n.3, p. 453-462. 2012. Disponível em: <http:// dx.doi.org/10.1590/S1981-77462012000300006>. Acesso em: 05 nov. 2015.

GIACOMOZZI, Andréia Isabel et al. Levantamento sobre uso de álcool e outras drogas e vulnerabilidades relacionadas de estudantes de escolas públicas participantes do programa saúde do escolar/saúde e prevenção nas escolas no município de Florianópolis. Saúde e Sociedade,São Paulo, v.21, n.3, p. 612-622. 2012. Disponível em: <http://dx.doi.org/10.1590/ S0104-12902012000300008>. Acesso em 05 nov. 2015.

GIL, Antônio Carlos. Métodos e Técnicas de Pesquisa Social. 2. ed. São Paulo: Atlas, 2008.

GRACIANO, Andréa Monteiro de Castro et al. Promoção da Saúde na Escola: história e perspectivas. Journal of Health \& Biological Sciences, Fortaleza, v. 3, n. 1, p. 34-38, mar. 2015. Disponível em: <http://201.20.109.36:2627/index.php/medicina/article/view/110>. Acesso em: 29 Jan. 2016. doi:10.12662/2317-3076jhbs.v3i1.110.p34-38.2015.

GREGO, Maria da Conceição et al. Oficina de autoexame de mamas: uma estratégia para o autoconhecimento de adolescentes. Acta Paulista de Enfermagem, São Paulo, v.24, n.4, p. 493-499. 2011. Disponível em: <http://www.scielo.br/scielo.php?script=sci_arttext\&pid $=$ S0103-21002011000400008>. Acesso em: 05 nov. 2015.

LAIGNIER, Mariana Rabello; CASTRO, Marlúcia de Almeida; SA, Paula dos Santos Cabral de. De olhos bem abertos: investigando acuidade visual em alunos de uma escola municipal de Vitória. Esc. Anna Nery, Rio de Janeiro, v.14, n.1, p. 113-119. 2010. Disponível em: <http://dx.doi. org/10.1590/S1414-81452010000100017>. Acesso em: 29 jan. 2016.

LIMA, Ferrari de; MALACARNE, Dartel; STRIEDER, Vilmar. O papel da escola na promoção da saúde - uma mediação necessária. EccoS Revista Científica, São Paulo, n. 28, p. 191-206, mai./ ago. 2012. Disponível em: <http://dx.doi.org/10.1590/S1414-81452010000100017>. Acesso em: 20 out. 2015.

MACIEL, Ethel Leonor Noia et al. Projeto Aprendendo Saúde na Escola: a experiência de repercussões positivas na qualidade de vida e determinantes da saúde de membros de uma comunidade escolar em Vitória, Espírito Santo. Ciência \& Saúde Coletiva, Rio de Janeiro, v.15, n.2, p. 389-396. 2010. Disponível em: <http://dx.doi.org/10.1590/S1413-81232010000200014>. Acesso em: 20 out. 2015.

MARCONI, Marina de Andrade; LAKATOS, Eva Maria. Fundamentos da Metodologia Científica. 5. ed. São Paulo: Atlas, 2003. 
MOHR, Adriana. A saúde na escola: análise de livros didáticos de $1^{\mathrm{a}}$ a $4^{\mathrm{a}}$ séries. Cad. Pesq., São Paulo, n. 94, p. 50-57, ago. 1995. Disponível em: <http://publicacoes.fcc.org.br/ojs/index.php/cp/ article/view/838/844>. Acesso em: 29 jan. 2016.

PEREIRA, Simone Cardoso Lisboa et al. Percepção de monitores do PET-Saúde sobre sua formação e trabalho em equipe interdisciplinar. Interface - Comunicação, Saúde, Educação, Botucatu, v.19, n.1, p. 869-878. 2015. Disponível em: <http://dx.doi.org/10.1590/1807-57622014.0840>. Acesso em: 21 dez. 2015.

PINHAO, Francine; MARTINS, Isabel. Diferentes abordagens sobre o tema saúde e ambiente: desafios para o ensino de ciências. Ciência \& Educação, Bauru, v.18, n.4, p. 819-836. 2012. Disponível em: <http://www.scielo.br/scielo.php?pid=S1516-73132012000400006\&script=sci_arttext>. Acesso em: 20 out. 2015.

RAMOS, Camila Irigonhé et al. A promoção da saúde na "terra do nunca": uma experiência Interdisciplinar. Revista Brasileira em Promoção da Saúde, Fortaleza, v.26, n.3, pp. 436-441, Jun./ set. 2013. Disponível em: <http://www.redalyc.org/articulo.oa?id=40829885018>. Acesso em: 06 nov. 2015.

SANTOS, Flavia da Oliveira; Lima, Samuel do Carmo. Hygeia: Revista Brasileira de Geografia Médica e da Saúde, Umberlândia, v. 11, n.20, pp.213-227, Jun. 2015. Disponível em: < http://www. seer.ufu.br/index.php/hygeia/issue/view/1309>. Acesso em: 05 de fev. 2015.

SANTOS, Flavia Pedro dos Anjos et al. Estratégias de enfrentamento dos dilemas bioéticos gerados pela violência na escola. Physis, Rio de Janeiro, v.21, n.1, pp. 267-281. 2011. Disponível em: <http://www.scielo.br/scielo.php?pid=S0103-73312011000100016\&script=sci_arttext>. Acesso em: 20 out. 2015 .

SANTOS, Maria Fernanda Oliveira et al. A intersetorialidade como meio de superar desafios em educação em saúde. Revista Brasileira de Medicina e Família da Comunidade, Florianópolis, v. 6, n. 21, p. 288-292, out./dez. 2011. Disponível em: <http://www.rbmfc.org.br/rbmfc/article/ view/319>. Acesso em: 20 out. 2015.

SILVEIRA, Rodrigo Eurípedes da et al. Oficinas com professores: educação em saúde para o manejo com adolescentes. Acta Paulista de Enfermagem, São Paulo, v.25, n.2, p. 169-174. 2012. Disponível em: <http://www.scielo.br/scielo.php?pid=S0103 21002012000900027\&script=sci_ arttext\&tlng=pt>. Acesso em: 20 out. 2015.

SILVA, Cristiane Maria da Costa et al. Educação em saúde: uma reflexão histórica de suas práticas. Ciência \& Saúde Coletiva, Rio de Janeiro, v.15, n.5, p. 2539-2550. 2010. Disponível em: <http://dx.doi.org/10.1590/S1413-81232010000500028>. Acesso em: 20 out. 2015.

SILVA, Pablo Cordeiro da; MARTINS, Alberto Mesaque; SCHALL, Virgínia Torres. Cooperação entre agentes de endemias e escolas na identificação e controle. Revista Brasileira em Promoção da Saúde, Fortaleza, v.26, n.3, p. 404-411, jul./set. 2013. Disponível em: <http://www.redalyc.org/ articulo.oa?id=40829885014>. Acesso em: 05 nov. 2015.

SILVA, Rosangela Dantas da et al. Mais que educar... ações promotoras de saúde e ambientes saudáveis na percepção do professor da escola pública. Revista Brasileira em Promoção da Saúde, Fortaleza, v.24, n.1, p. 63-72, jan./mar. 2011. Disponível em: <http://ojs.unifor.br/index. php/RBPS/article/view/2053>. Acesso em: 05 nov. 2015.

SILVA, Kelanne Lima da et al. Reflexões acerca do abuso de drogas e da violência na adolescência. Escola Anna Nery, Rio de Janeiro, v.14, n.3, p. 605-610. 2010. Disponível em: <http:// 
www.scielo.br/scielo.php?pid=S1414-81452010000300024\&script=sci_arttext $>$. Acesso em: 05 nov. 2015.

SILVA, Marta Angélica Iossi; MELLO, Débora Falleiros de; CARLOS, Diene Monique. O adolescente enquanto protagonista em atividades de educação em saúde no espaço escolar. Revista Eletrônica de Enfermagem, Goiânia, v. 12, n. 2, p. 287-293. 2010. Disponível em: <http://www. fen.ufg.br/revista/v12/n2/v12n2aog.htm>. Acesso em: 29 jan. 2016.

SOUZA, Manoel Messias Alves de et al. PROMOÇÃO DE OMPORTAMENTOS SAUDÁVEIS EM PRÉ-ESCOLARES. Revista Brasileira em Promoção da Saúde, Fortaleza, v. 26, n. 3, p. 387-395, jul./set. 2013. Disponível em: <http://redalyc.org/articulo.oa?id=40829885012>. Acesso em: 05 nov. 2015.

THOMPSON, Bárbara Morais; BRANDÃO, Gilberto Oliveira. Relação entre educação e saúde no ensino de ciências: uma reflexão, Brasília, 2013. Disponível em: <http://repositorio.uniceub.br/ bitstream/235/6462/1/21035017.pdf>. Acesso em: 29 jan. 2016.

\section{DADOS DAS AUTORAS}

\section{VANESSA TERESINHA RIBEIRO}

Mestranda em Educação pela Universidade de Pernambuco. Petrolina/PE - Brasil. vanessa.ribeiro@ifpi.edu.br

\section{Cristhiane Maria Bazílio de OMena Messias}

Doutora em Ciências pela Universidade Federal de Alagoas. Petrolina/PE - Brasil. cristhiane.omena@upe.br

Submetido em: 12-3-2016

Aceito em: 27-12-2016 